\title{
MRD Tailored Therapy in AML: What We Have Learned So Far
}

\author{
Lok Lam Ngai, Angèle Kelder, Jeroen J. W. M. Janssen, Gert J. Ossenkoppele \\ and Jacqueline Cloos*
}

Department of Hematology, Amsterdam UMC, Cancer Center Amsterdam, Vrije Universiteit, Amsterdam, Netherlands

Acute myeloid leukemia (AML) is a heterogeneous clonal disease associated with a dismal survival, partly due to the frequent occurrence of relapse. Many patient- and leukemia-specific characteristics, such as age, cytogenetics, mutations, and measurable residual disease (MRD) after intensive chemotherapy, have shown to be valuable prognostic factors. MRD has become a rich field of research where many advances have been made regarding technical, biological, and clinical aspects, which will be the topic of this review. Since many laboratories involved in AML diagnostics have experience in immunophenotyping, multiparameter flow cytometry (MFC) based MRD is currently the most commonly used

OPEN ACCESS

Edited by:

Alessandro Isidori, AORMN Hospital, Italy

Reviewed by:

Sangeetha Venugopal,

University of Texas MD Anderson Cancer Center, United States Antonio Curti,

University of Bologna, Italy Eva Barragan,

La Fe Hospital, Spain

*Correspondence:

Jacqueline Cloos j.cloos@amsterdamumc.nl

Specialty section:

This article was submitted to Hematologic Malignancies, a section of the journal Frontiers in Oncology

Received: 07 September 2020 Accepted: 16 November 2020 Published: 15 January 2021

Citation:

Ngai LL, Kelder A, Janssen JJWM, Ossenkoppele GJ and Cloos J (2021) MRD Tailored Therapy in AML: What We Have Learned So Far. Front. Oncol. 10:603636. doi: 10.3389/fonc.2020.603636 method. Although molecular, quantitative PCR based techniques may be more sensitive, their disadvantage is that they can only be applied in a subset of patients harboring the genetic aberration. Next-generation sequencing can assess and quantify mutations in many genes but currently does not offer highly sensitive MRD measurements on a routine basis. In order to provide reliable MRD results, MRD assay optimization and standardization is essential. Different techniques for MRD assessment are being evaluated, and combinations of the methods have shown promising results for improving its prognostic value. In this regard, the load of leukemic stem cells (LSC) has also been shown to add to the prognostic value of MFCMRD. At this moment, MRD after intensive chemotherapy is most often used as a prognostic factor to help stratify patients, but also to select the most appropriate consolidation therapy. For example, to guide post-remission treatment for intermediate-risk patients where MRD positive patients receive allogeneic stem cell transplantation and MRD negative receive autologous stem cell transplantation. Other upcoming uses of MRD that are being investigated include: selecting the type of allogeneic stem cell transplantation therapy (donor, conditioning), monitoring after stem cell transplantation (to allow intervention), and determining drug efficacy for the use of a surrogate endpoint in clinical trials.

Keywords: MRD - measurable residual disease, AML - acute myeloid leukemia, LSC-leukemic stem cells, MRDdriven therapy, MRD-tailored therapy

\section{INTRODUCTION}

Acute myeloid leukemia (AML) is a heterogeneous clonal disease that remains to have low overall survival (OS) despite recent developments of better supportive care and emerging targeted therapies (1). Death often results from relapse after an initial successful induction treatment that led to a complete remission (CR). This relapse is often inherently drug-resistant (2) (Figure 1). Many patient- and leukemia-specific 


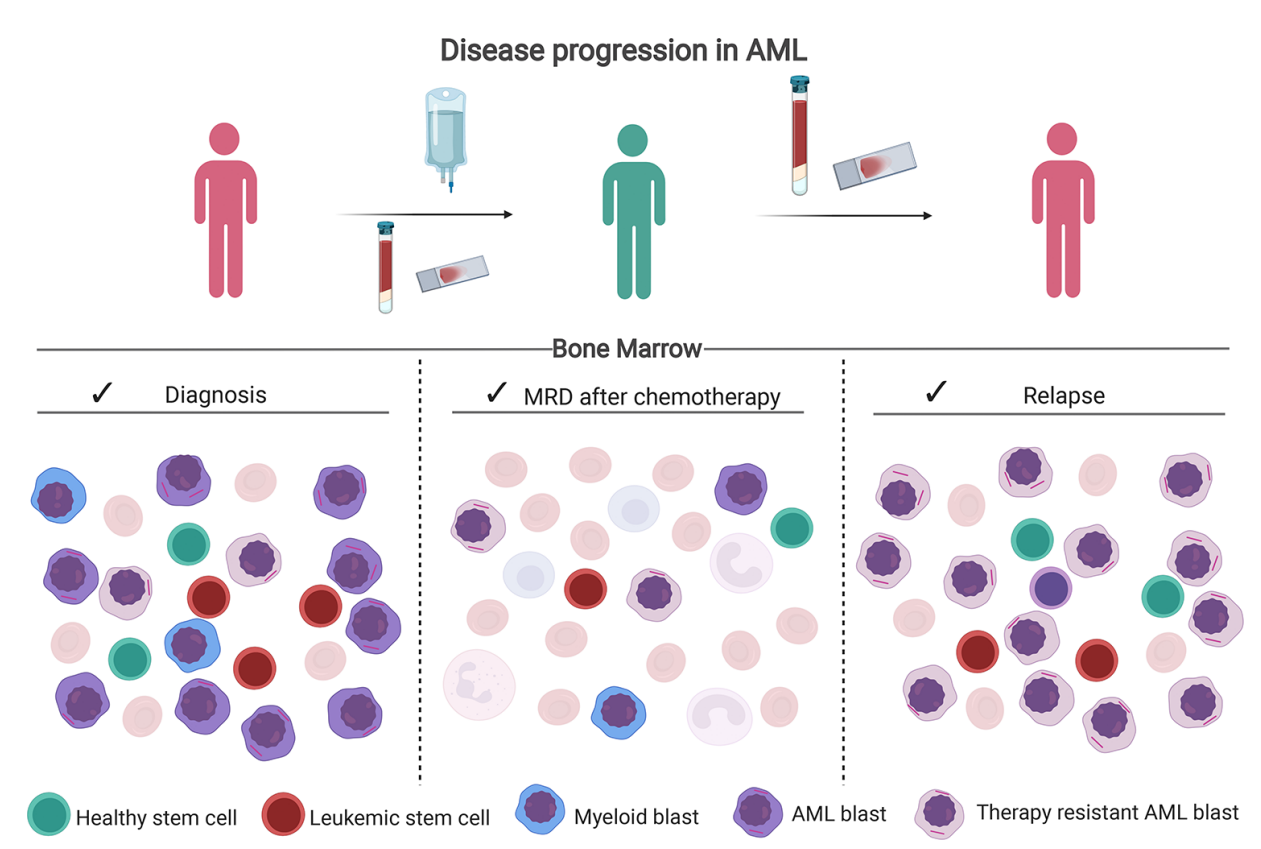

FIGURE 1 | Disease progression in AML. After therapy, chemotherapy-resistant leukemic blasts and leukemic stem cells can remain in the bone marrow. Assessment of the percentage of residual leukemia cells after chemotherapy via multiparameter flow cytometry (MFC) or molecular methods is called MRD. In particular, the presence of leukemia stem cells (LSC) is of prognostic relevance as they are presumed to initiate the relapse. Created with BioRender.com.

characteristics are associated with clinical outcome such as age, cytogenetics and mutational profile determined before treatment, and measurable residual disease (MRD) determined after intensive chemotherapy (3).

MRD measurement in AML is challenging due to the highly clonal nature of the disease. However, several different techniques to assess MRD are currently being investigated, and their prognostic value is being validated. The potential uses of MRD in the clinical practice such as selecting appropriate consolidation therapy based on MRD or the usage of MRD as a surrogate endpoint are also currently being explored (partly summarized in Figure 2).

In this review, we will present the differences between MRD assessment techniques, developments of MRD, current literature that gives evidence for MRD-tailored strategies, and future perspectives in the use of MRD for the clinic.

\section{MEASURABLE RESIDUAL DISEASE IN ACUTE MYELOID LEUKEMIA- DIFFERENT TECHNIQUES}

\section{Multiparameter flow cytometry MRD (MFC-MRD)}

Since many laboratories involved in AML diagnostics have experience in immunophenotyping, MFC-MRD is currently the most commonly used method to determine MRD. The technique is accessible and widely applicable for about $90 \%$ of the AML patients (4). However, a high level of expertise is needed to perform MFC-
MRD accurately, and its sensitivity limit is around $10^{-4}-10^{-5}$ (Table 1) $(4,13)$. The expertise includes not only the technique but also the selection of the right antibody panel, standardized flow data analysis, and extensive knowledge about normal bone marrow (BM) expression patterns of the selected cluster of differentiation (CD) markers. Moreover, since MRD is assessed after intensive chemotherapy, knowledge of regenerative BM CD marker expression patterns is crucial (14). MFC-MRD measures the load of leukemic blasts (immature blasts markers: CD34, CD117, and CD133) within the white blood cells (WBC) fraction. Their aberrant expressions are grouped by: cross lineage expressions of non-myeloid CD markers on myeloid blasts (e.g., CD7, CD56), asynchronous expression of mature CD markers on immature cells (e.g., CD11b), lack of expression (CD13, CD33) or overexpression (CD33, CD34) of CD markers. These leukemic blasts are referred to as leukemia-associated immunophenotypes (LAIPs). MFC-MRD is calculated as the percentage of LAIP positive cells within the total WBC measured in BM.

Generally, there are two approaches to assess MFC-MRD: The LAIP-based approach where the LAIP is assessed at diagnosis and followed during therapy and the Different from Normal (DfN) approach in which any aberrant pattern of cell surface markers compared to their combined expression in normal $\mathrm{BM}$ are designated as being residual leukemic disease. The LAIP-based approach measures only the dominant LAIPs detected at diagnosis and holds the risk of false negativity, because LAIPs that arise due to clonal evolution will be missed (15). While the DfN approach will identify LAIPs that arise due to clonal evolution, it has the risk of potential false positivity of 


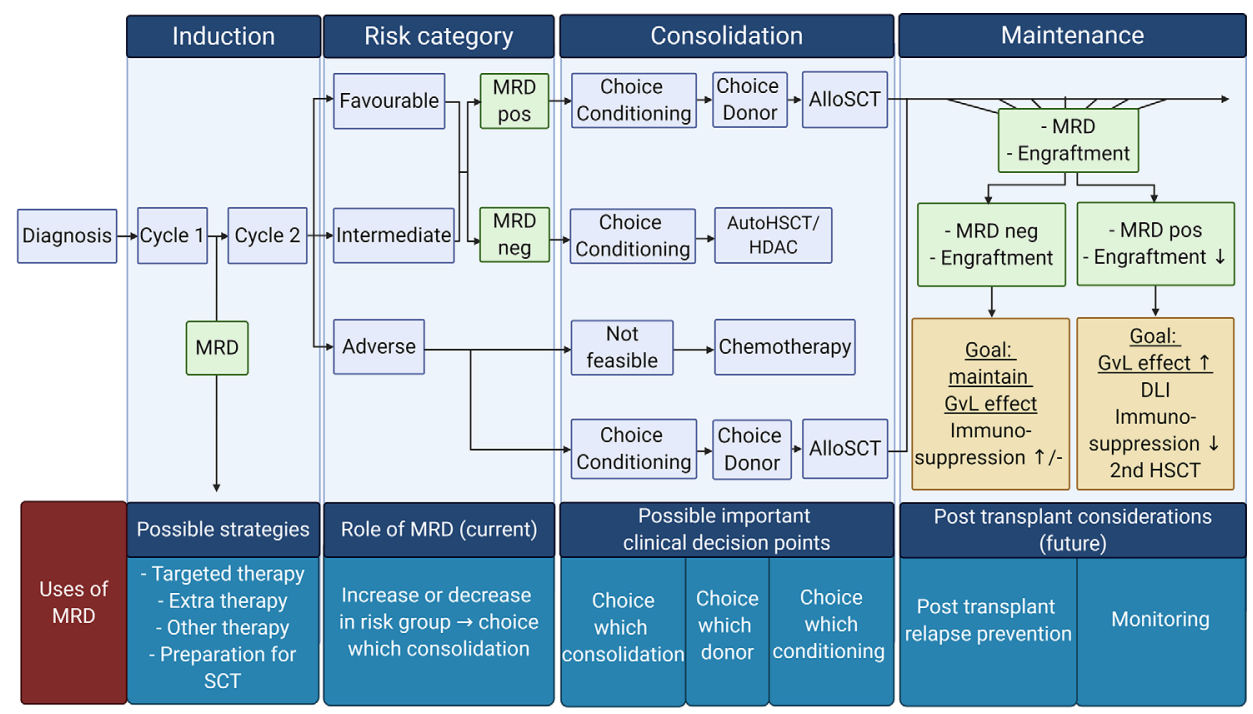

FIGURE 2 | Overview of possible MRD tailored therapy in different AML treatment phases: Current use of MRD tailored therapy focuses on the choice of consolidation therapy (post-remission therapy). However, other uses of MRD are also emerging. Future possibilities for MRD usage in the clinic can be the choice in conditioning treatment, donor in the consolidation phase, and prevention of relapse strategies in the maintenance phase. Pos, positive; Neg, negative; AutoSCT, autologous hematopoietic stem cell transplantation; HDAC, high doses cytarabine; AlloSCT, allogeneic hematopoietic stem cell transplantation; GvL, Graft versus Leukemia; DLI, donor lymphocytes infusion. Created with BioRender.com.

transient immunophenotypic shifts that occur in regenerative BM after therapy (15). Although different LAIPs have variable sensitivity and specificity due to varying background levels of the LAIP in normal BM, this is in particular variable in regenerating $\mathrm{BM}(16,17)$. In the ELN 2018 MRD guidelines, an integrated LAIP-based DfN approach was recommended. Several studies have been using this LAIP-based DfN approach where LAIPs at diagnosis were assessed, but also DfN patterns at follow up were analyzed $(16,18,19)$. The dominant LAIPs at diagnosis, LAIPs that arise due to clonal evolution, and the immunophenotypic shifts after therapy are taken into account with this approach. The LAIP-based DfN approach may be essential to gain information about the efficacy of novel drugs that target against the dominant clone. An interesting feature from the LAIP method is that the antibody panel can then be adjusted to include the marker of interest to assess the effectivity of the treatment to the target cells present at diagnosis (e.g., CLEC12A, CD123) (20, 21).

TABLE 1 | Different MRD techniques with availability and sensitivity.

\begin{tabular}{|c|c|c|}
\hline Method & Availability & Sensitivity \\
\hline Morphology (5) & $100 \%$ & $5 \times 10^{-2}(5 \%)$ \\
\hline Cytogenetics (6) & $70 \%$ & $1-5 \times 10^{-2}$ \\
\hline FISH (7) & $40 \%$ & $1 \times 10-2$ \\
\hline (Real-time) RT-PCR* (8-10) & $20-40 \%$ & $1 \times 10^{-3}-1 \times 10^{-6}$ \\
\hline Next generation sequencing ${ }^{\star}(11)$ & $80-90 \%$ & $1 \times 10^{-3}-1 \times 10^{-4}$ \\
\hline $\begin{array}{l}\text { Flow cytometry }(4,12) \\
\text { (Immunophenotyping) }\end{array}$ & $80-90 \%$ & $1 \times 10^{-4}-1 \times 10^{-5}$ \\
\hline
\end{tabular}

FISH, fluorescent in situ hybridization; RT-PCR, reverse transcription-polymerase chain reaction. *Sensitivity dependent on gene.

\section{Molecular Measurable Residual Disease}

Molecular PCR based techniques have higher sensitivity than MFC MRD, depending on the specific gene and the used molecular technique (Table 1) (5). The chosen genes for the MRD assay should be stable genes during disease progression, such as NPM1, RUNX1-RUNX1, or CBF-MYH11 (5, 22, 23). Although FLT3 harbors frequent recurring mutations, the internal tandem duplication (FLT3/ITD) is highly unstable and can be gained or lost during therapy $(24,25)$. Some research groups still show its potential as a good prognosticator since the presence of the FLT3/ ITD is a strong indicator of residual disease (26-28). However, FLT3/ITD negativity does not imply that residual leukemia cells are absent, and therefore highly sensitive techniques will be required to ensure FLT3/ITD negativity $(29,30)$.

The detection of Wilms' tumor 1 (WT1) by mutation and expression, has also been suggested to be useful for disease monitoring (31). Its impact for AML was recently reviewed by Luo et al. (32). The ELN 2018 MRD guidelines stated that WT1 expression is not preferable to use as a MRD marker and should only be used when there is no other MRD marker available.

\section{ADVANCES IN CURRENT MEASURABLE RESIDUAL DISEASE TECHNIQUES}

\section{Multiparameter Flow Cytometry- Measurable Residual Disease Protocol, Harmonization, and Standardization}

A drawback of MFC-MRD is that the assay is technically heterogeneous because each laboratory employs its own 
expertise. Therefore, the comparison of MFC-MRD data between laboratories is complex and its accuracy is hard to interpret. To properly apply and interpret the MFC-MRD results, the assay should fulfill specific requirements, including accurate sample preparation, instrument settings, panel design, awareness of normal and regenerating BM, gating strategies, and a clinically validated cut off point for MRD positivity (at a particular time point during therapy). Furthermore, to get further insight into important clinical subgroup analyses and optimization of the assay for clinical decision making, meta-analyses of currently available data is crucial. To combine the multicenter data, standardization where necessary and harmonization where possible have been the emphasis in MFC MRD in the past few years (15, 33-35). Apart from the multicenter use of data, the use of MFC-MRD in clinical decision making has made it even more important to standardize and qualify the assay.

To provide a reliable and valid MRD result, the assay should be qualified by In Vitro Diagnostic Rules (IVDR). These prerequisites are mandatory for approval of the U.S. Food and Drug Administration (FDA) to qualify MFC-MRD as a biomarker in $\mathrm{AML}(36,37)$. Important recommendations relate to the usage of $\mathrm{BM}$ preferably (to avoid false negatives) and provide markers used in the MFC-MRD assay that can distinguish between the aberrant immunophenotype and regenerating $\mathrm{BM}$ (to avoid false positives).

sFor the qualification of MFC-MRD and to ensure the reliability of the assay, validation experiments about the accuracy, specificity, sensitivity, stability, and several comparisons, such as interlaboratory comparisons should be made (37). Furthermore, FDA approval requires that the detection threshold should be tenfold lower than its clinically relevant cut-off point. For MFC-MRD, the consensus for the MRD cut-off is $0.1 \%$ LAIP+ cells on WBC at the post-induction measurement (38). With this $0.1 \%$ cut-off, the lower limit of quantification for the detection threshold would be $0.01 \%$.

\section{The Relevance of Leukemic Stem Cells}

One of the methods to refine the current MFC-MRD assessment is to include the identification of relapse initiating cells that are capable of repopulating a new leukemia and that are highly chemotherapy-resistant (39-42). In AML, these have been shown to be the leukemic stem cells (LSC), which are characterized by $\mathrm{CD} 34^{+} \mathrm{CD} 38^{-}$expression in combination with an aberrant (LSC) marker not present on normal hematopoietic stem cells (HSC) (43). The LSC load at diagnosis and follow-up has a prognostic value either alone or together with the MFC-MRD results (44-49). Nevertheless, the development to incorporate LSC in the MFC-MRD assessment is still not on the level of the MFC-MRD regarding the technical recommendations. Standardization and harmonization will be one of the next developments in the LSC detection. Current initiatives show that the harmonization and reproducibility of LSC measurement and analysis between several centers is possible $(50,51)$.

Still, more expertise needs to be acquired to give better general recommendations and show the robustness of the LSC assay. Because the frequency of LSCs in AML is lower than MRD, more events are needed for acquisition to obtain a reliable result (40, 52). Also, LSCs are highly heterogeneous in their LSC marker positivity, and clonal evolution can result in shifts of specific LSC markers during therapy (53). Multiple LSC markers are thereby crucial in the same LSC detection panel. Since the current panels used for MFC MRD are 8-10 colors, this would require many tubes and subsequently (too) many WBCs to accurately measure LSCs. Therefore, a one-tube assay was developed with six LSC markers combined in the PE channel, and its technical reproducibility has been multicenter validated $(34,50,54)$. Advantages of including multiple LSC markers in the Combi PE channel are that 1) new potentially relevant LSC markers can be added to this Combi channel, 2) when an LSC marker is a treatment target (e.g., CLL-1), this LSC marker can be taken out of this channel and placed into the backbone for monitoring during treatment, and 3) due to more markers in one channel, potential upcoming LSC clones during therapy, that were undetected at diagnosis, can still be found in follow-up setting. New potential LSC markers are still being investigated (53, 55, 56). As a future perspective, more extensive LSC panels may be possible because of the technical developments in the flow cytometry field, e.g., spectral flow cytometers where panels with more than 18 colors can be designed (57).

\section{Advances in Molecular Measurable Residual Disease}

For molecular PCR, Real-Time quantitative PCR (RT-qPCR) is most commonly used. Recent novel developments of digital droplet PCR (ddPCR) show that this might be more sensitive and more specific than RT-qPCR (58-61). One disadvantage of molecular MRD techniques is that the method can only be applied to patients harboring the mutation $(4,8)$. To account for this disadvantage, NGS can assess and quantify mutations in many genes (62). However, NGS still needs much investigation and optimization before it can be implemented standardly in routine diagnostics $(63,64)$. The heterogeneous sensitivity of NGS between laboratories is currently one issue that prevents that NGS-MRD be implemented in the routine diagnostics [reviewed in (65)]. In the ELN 2018 MRD recommendations, no concrete recommendations were described to ensure good standardization and harmonization for NGS (38). However, suggestions for reporting NGS-based AML MRD have been described in several reviews $(62,66)$. Which clinical time point, what tissue and quality of the sample were examples of these suggestions. In addition, the method to correct the error in NGS should also be reported (66). Correcting error in NGS can be done by physical error correction where unique molecular identifiers are added in the sample DNA or by computational error correction [reviewed in $(65,67)]$.

One of the challenges for NGS is the Clonal Hematopoiesis of Indeterminate/oncogenic Potential (CHIP) detection, which are potential pre-leukemic mutations that increases in frequency during higher age $(62,68)$.These genes (e.g., DNMT3A, TET2, and ASXL1) were not correlated with an increased relapse rate and may impact on the specificity of the assay (69). Therefore, these genes are recommended to be excluded for MRD detection (38). To prevent false positives with NGS-MRD and for 
validation, more research should be done to determine these CHIP mutations and consensus should be made on which CHIP mutations can be excluded (66).

\section{Combinations of Different Techniques}

The development of various MRD measuring techniques increases the options to measure MRD more accurately. However, these increasing options also complicates the appropriate use of MRD. Each technique has its sensitivity and specificity at different conditions, such as which AML type, tissue, time point, and threshold.

By combining different MRD measurement techniques, a very poor risk group of AML patients who are double-positive can be identified, which indicates that the methods, although not completely concordant, complement each other (69-73). The use of combined techniques would necessitate laboratories to have the expertise for each technique. For instance, in HOVON studies, MFC-MRD is assessed in the central laboratory of the Amsterdam UMC, location VUMC in Amsterdam, while molecular $\mathrm{MRD}$ is assessed in the central laboratory of the Erasmus MC in Rotterdam (69). The complementary results of RT-qPCR NPM1 and MFC-MRD urged us to assign MRD positivity to patients that are positive for either or both of the techniques in our current trials. These data are also found by others $(70,71)$ and is currently an important research topic. In particular, to unravel the basis for the discrepancy between both techniques in the discordant cases.

\section{EMPLOYMENT OF MEASURABLE RESIDUAL DISEASE IN THE CLINIC}

\section{The Current Well-Established Use of Measurable Residual Disease in the Clinic}

In the clinical setting, MRD is currently used to refine the complete remission (CR) status that is assessed by morphology $(74,75)$. Most studies show the prognostic value of MFC-MRD and molecular MRD, particularly before transplantation $(3,63$, 76-81). Measuring MRD at other time points can also have prognostic value and can help to identify a group with poor prognosis, such as MRD measurement after the first chemotherapy $(3,18,82)$ and after the consolidation phase $(3$, $83,84)$.

In an international survey of clinicians specialized in AML treatment, clinicians were asked about the use of MRD in their clinical decision making. It appeared that although the availability of qualified MRD assessments is often limited, MRD is currently widely used in the United States (85). In this survey, clinicians used MRD measurements mostly after consolidation (59\%) before transplant (64\%), and also after transplant (48\%), which is remarkable, as MRD validity outside the pre-transplant setting is not yet validated. For ensuring the accuracy of the MRD assessment in real-life MRD utilization, it is essential to have a qualified assay, to define standard time points, and to set thresholds that have proven validity in prospective clinical studies.

\section{In the Near Future: Measurable Residual Disease Tailored Therapy}

In the past few years, several definitions for MRD usage in the guidance of the therapy choice have been published, such as MRD driven or MRD directed therapies (Table 2) (70, 86-88). Currently, broadly two MRD driven strategies can be categorized (Table 2): 1. MRD use in the pre-transplant setting, such as selecting the most appropriate consolidation therapy. 2. MRD use in the post-transplant setting, such as taper off maintenance therapy or manage the Graft versus Leukemia effect.

\section{Measurable Residual Disease Use in Pre-transplant Setting}

Post-Induction Measurable Residual Disease to Select the Optimal Post-Remission Treatment

Currently, the standard strategy to eradicate AML is intensive chemotherapy in repetitive cycles or followed by hematopoietic stem cell transplantation, with allogeneic stem cell transplantation (alloSCT) having superior anti-leukemic activity compared to autologous stem cell transplantation (autoSCT) $(75,89)$. However, given its potential toxicity, alloSCT would preferably be averted in those who do not need it $(90,91)$. A few published studies that intensified treatment based on MRD in pediatric AML $(92)$ and $t(8,21)$ patients (86) suggested that this type of MRD-guided therapy may improve outcome.

In many protocols, alloSCT is recommended for the adverse genetic risk group that have a high relapse risk, and often also for the intermediate-risk group (75). For this latter group, MRD may be used to guide consolidation treatment $(75,93,94)$. The GIMEMA AML 1310 trial (70) suggested that the adverse prognostic effect of MRD positivity in the intermediate-risk group before transplantation can be improved by performing alloSCT. MRD positive $(>0.035 \%)$ patients, who were treated with alloSCT, performed equally well as MRD negative patients who received autoSCT (22), but here historical controls were used. The results of the prospective HOVON 132 study, where MRD guided treatment was used in the intermediate group to decide for either allo- or autoSCT, are eagerly awaited. Still, in none of these, or any of the planned studies as checked at clinicaltrials.gov, a randomized comparison was or will be performed to test the value of either conventional treatment or alloSCT in MRD positive intermediate-risk group patients (Table 2). Nevertheless, since MRD is the most important prognostic factor after intensive chemotherapy, new HOVON/ SAKK protocols will continue to guide consolidation treatment on MRD levels after induction treatment (95).

\section{Measurable Residual Disease Elimination Strategy Before Transplantation}

The upcoming use of MRD in the clinic also provides new challenges and possibilities for the usage of MRD before transplantation (Figure 2). Some retrospective studies indicate that non-acute promyelocytic leukemia (APL) patients who undergo SCT with an MRD positive result had a poor OS even when they convert to MRD negative after SCT $(96,97)$. Therefore it can be hypothesized that these patients could benefit from extra 
TABLE 2 | Current studies where MRD is incorporated in the decision making for AML.

\begin{tabular}{|c|c|c|c|c|c|c|}
\hline & Clinicaltrials.gov & $\mathbf{n}$ & Terms used & Age & Group & Technique \\
\hline \multicolumn{7}{|l|}{ Induction } \\
\hline MRD use in choosing targeted therapy & NCT03537560 & 300 & $\begin{array}{l}\text { MRD } \\
\text { directed }\end{array}$ & $>20$ & De novo & PCR, MFC \\
\hline MRD use in intensifying treatment at induction & NCT03769532 & 28 & MRD guided & $>18$ & NPM1 & PCR NPM1 \\
\hline \multirow[t]{2}{*}{ MRD use in choosing extra therapy } & NCT02349178 & 6 & NA & $<39$ & $\mathrm{MRD}+$ & MFC, molecular \\
\hline & NCT03989713 & 80 & $\begin{array}{l}\text { MRD } \\
\text { triggered }\end{array}$ & $18-75$ & Relapse/refractory & MFC \\
\hline \multicolumn{7}{|l|}{ Before transplant } \\
\hline \multirow[t]{10}{*}{$\begin{array}{l}\text { MRD use in risk stratification and choice } \\
\text { consolidation }\end{array}$} & NCT02870777 & 743 & $\begin{array}{l}\text { MRD } \\
\text { directed }\end{array}$ & $18-60$ & Low/intermediate & Unknown \\
\hline & NCT01041040 & 200 & $\begin{array}{l}\text { Risk } \\
\text { adapted }\end{array}$ & All & All & MFC \\
\hline & NCT03846362 & 100 & MRD based & $<18$ & Intermediate/high & PCR, MFC \\
\hline & NCT04168502 & 414 & MRD driven & $18-60$ & Favorable/intermediate & Unknown \\
\hline & NCT03515707 & 30 & NA & $18-69$ & $\begin{array}{l}\text { Favorable/intermediate MRD } \\
\text { negative }\end{array}$ & $\begin{array}{l}\text { MFC, cytogenetics, FISH, } \\
\text { molecular }\end{array}$ \\
\hline & NCT03620955 & 1000 & $\begin{array}{l}\text { Risk } \\
\text { stratified }\end{array}$ & $14-60$ & De novo & MFC \\
\hline & NCT04174612 & 172 & NA & $18-65$ & FLT3 & MFC \\
\hline & NCT02272478 & 1600 & NA & $>60$ & De novo & MFC \\
\hline & NCT01723657 & 862 & $\begin{array}{l}\text { Risk } \\
\text { adapted }\end{array}$ & $18-70$ & De novo & MFC \\
\hline & NCT03417427 & 100 & NA & $14-60$ & Intermediate & MFC \\
\hline \multicolumn{7}{|l|}{ Post-transplant } \\
\hline \multirow[t]{2}{*}{$\begin{array}{l}\text { MRD use in } \\
\text { post-transplant intervention }\end{array}$} & NCT02458235 & 67 & $\begin{array}{l}\text { Risk } \\
\text { adapted }\end{array}$ & $<29$ & Post-transplant & MFC, gene expression profiling \\
\hline & NCT03121079 & 29 & NA & $18-60$ & Standard & Flow and RQ-PCR WT1 \\
\hline \multirow[t]{2}{*}{ MRD use in tapering treatment } & NCT02458235 & 67 & $\begin{array}{l}\text { Risk } \\
\text { adapted }\end{array}$ & $<29$ & Post-transplant & MFC, gene expression profiling \\
\hline & NCT03466294 & 42 & NA & $>60$ & De novo/elderly & Unknown \\
\hline
\end{tabular}

NA, not described/not available; NPM1, nucleophosmin 1; FLT3, fms like tyrosine kinase 3; MFC, multiparameter flow cytometry MRD; RQ-PCR, real-time quantitative polymerase chain reaction; WT1, Wilms' Tumor 1; FISH, fluorescence in situ hybridization.

pre-emptive treatment before transplantation $(96,97)$. Bataller and colleagues looked into the usage of pre-emptive therapy after molecular failure, classified as the increase of MRD after treatment or failure to achieve molecular response after treatment (98). They divided the ELN favorable risk NPM1 MRD positive patients into two groups: one where patients proceeded directly to alloSCT and the other where patients received additional therapy before proceeding to alloSCT (69). The choice of additional treatment was based on the individual situation of the patient (98). No difference in 2-year OS was seen between the molecular failure group receiving extra pre-emptive treatment and the group that directly proceeded to alloSCT (81.5 versus $90 \%$, respectively) (98). Compared to the patients that had a morphological relapse and proceeded to alloSCT after receiving salvage therapy, patients classified with molecular failure had a higher 2-year OS (morphological relapse vs. molecular failure, 42 vs. $85.7 \%$, respectively). The authors concluded that pre-emptive therapy had a favorable outcome in ELN favorable risk NPM1 positive AML patients. However, because the choice of pre-emptive therapy and direct alloSCT was not randomized and the group of molecular failure consisted of small numbers, this finding needs to be validated and confirmed in a different trial. In another trial (openlabel phase II RELAZA2 trial), azacitidine was administrated to NPM1, RUNX1-RUNX1, or CD34+ mixed donor chimerism patients, who were MRD positive after conventional chemotherapy or SCT, and its effect was evaluated after six cycles (87). Of the 53 patients, $58 \%(\mathrm{n}=31)$ had an overall response in MRD (major + minor response) after azacitidine administration; 61\% ( $\mathrm{n}=19)$ converted from MRD positive to MRD negative (major response), and $39 \%(n=12)$ had a decrease in MRD (minor response). Furthermore, in the patients treated with only conventional chemotherapy, $48 \%(14 / 29)$ had an overall response (major + minor response) to azacitidine.

This trial shows that pre-emptive treatment can convert MRD positive to negative. However, because administering extra preemptive treatment may delay the option of SCT, the chosen treatment should be fast and effective. As these trials contained small numbers, the issue of achieving MRD negativity in AML through additional chemotherapy before transplant deserves further study. In addition, MRD based approaches may have to be evaluated extensively with the wider use of novel drugs, which have recently being approved and entered the clinical stage under normal clinical practice (real-life), such as FLT3 inhibitors and IDH1/IDH2 inhibitors. These novel targeted treatments display different anti-tumor mechanisms than the conventional intensive chemotherapy, which may impact MRD levels and kinetics. Potential "deeper" remissions may be established with targeted drugs that can be tracked based on the specific characteristic of the drug such as FLT3-ITD measurements when FLT3 inhibitors are used (99). Slower remissions may be achieved with differentiation inducing and lower-intensity therapies (100). The impact of these novel targeted therapies on the specific properties of MRD (time points, threshold, 
technique) and the optimal clinical application of MRD are currently being investigated (Tables 2 and $\mathbf{3}$ ).

\section{Measurable Residual Disease and Its Impact on Donor- and Conditioning Regimen Choice}

When used as prognostic factor, MRD should be assessed at an appropriate time point before transplant (38). As some studies have shown that an early search for a donor improves OS (82, $101,102)$, MRD positivity at an earlier time point may guide the urgency of searching a donor for alloSCT in the future.

Also, persistent MRD positivity before transplant may be an indication to select a haploidentical donor instead of a matched sibling donor to increase the Graft versus Leukemia effect (103105), whereas MRD-negative patients may be spared this intensive treatment modality (103).

Whether persistent MRD positivity should guide the intensity of conditioning is an unsolved issue. In a recent study by Dillon and colleagues, no effect of conditioning regimen intensity or donor type on OS was seen in NPM1 mutated AML patients who remained MRD positive before transplant (106). Similarly, no effect of conditioning regimen intensity was also observed in other studies that measured MRD with MFC-MRD (107-109). However, in another study, MFC-MRD positive patients receiving reduced-intensity conditioning had a higher chance of relapse, which was not observed in the MFC-MRD positive patients receiving myeloablative conditioning (110). This finding suggests that myeloablative conditioning had a positive effect on lowering the relapse rate (110). In another randomized study, NGS-MRD positive patients who received myeloablative conditioning had lower relapse rates and higher 3-year OS than those with reduced-intensity conditioning (1-year cumulative incidence: 15 versus 58\%, and 3-year OS, 61 versus 43\%, respectively) (64). This difference in 3-year OS was not observed in the NGS-MRD negative group (63 versus 56\%, respectively), probably due to the increased treatment-related mortality in the NGSMRD negative group. With these conflicting results, the role of MRD on the conditioning or donor choice remains to be further investigated.

\section{Measurable Residual Disease Use After Transplantation}

$\mathrm{MRD}$ assessment may also be useful to monitor disease kinetics after SCT and to test interventional strategies to prevent relapse occurrence (111). These include the use of hypomethylating agents (HMA), intensive chemotherapy, second alloSCT, immunosuppression adjustments, and donor lymphocyte infusions (DLI) (112-115). In a retrospective study including patients with myeloid malignancies undergoing SCT, patients who were followed by regular qPCR after transplant had a better survival compared to those with intramedullary and hematological relapses, probably due to earlier post-transplant interventions (112). In the RELAZA and RELAZA2 trial, administrating HMA to NPM1, RUNX1-RUNX1, or CD34+ mixed donor chimerism patients who were MRD positive after SCT could prevent or delay a hematological relapse $(87,116)$. Similar beneficial effects on decreasing MRD after MRD positivity by HMA were also found in CBF-AML and older patients $(117,118)$, although it needs to be established whether this translates to improved survival. Currently, the potential benefit of maintenance therapy after the treatment protocol is being investigated, and MRD may be useful to taper off maintenance therapies such as described for HMA and venetoclax (88).

The interval and duration of MRD monitoring after the end of therapy is still unclear. A survey, distributed among European Bone Marrow Transplantation centers, showed that MRD monitoring after transplantation was most often performed every 2-3 months after transplantation until a wide span of 15 years post-transplant (119). Since relapse after alloSCT commonly occurs within the first 2 years (106, 120-122), in particular the first year, seems to be the most valuable to perform MRD and detect an early increase in residual disease. However, more research is needed to determine the exact intervals for MRD monitoring, and on-time administrating pre-emptive therapy to prevent relapse (123).

Because MRD monitoring requires repetitive and relatively invasive $\mathrm{BM}$ aspirations, reliable MRD monitoring on peripheral blood $(\mathrm{PB})$ is highly desirable for achieving better patient comfort. Several studies have shown that MFC-MRD assessment in PB is possible but is about one log less sensitive, although it coincides with an increase in specificity $(124,125)$. Other techniques such as RT-qPCR MRD have also looked into monitoring the disease at multiple time points and also suggest that $\mathrm{PB}$ would be an alternative for intensive monitoring in CBFAML $(126,127)$. It has to be emphasized that a clinically relevant MRD threshold after post-remission therapy and its potential consequences on interventions has not been determined yet and requires further investigation.

\section{Future Perspectives Measurable Residual Disease as a Surrogate Endpoint}

In the last few years, more promising targeted therapies are emerging. However, the long duration of AML trials (e.g., Ratify trial 8 years) to assess a significant effect of a new drug is a limitation to push the development of AML treatments forward (128). An early endpoint as a surrogate for OS or event-free survival would therefore be highly desirable. MRD measurement could fulfill this role. To make MRD eligible for surrogacy, several requirements have to be met such as the qualification of the assay, clinical validation of the relationship for surrogacy and survival benefit (129) (Figure 3).

Although MRD is not officially recognized as a surrogate endpoint, some trials (clinicaltrials.gov) include MRD as one of the primary endpoints (Table 3). These trials are mostly phase I/ II studies that include CR based on MRD ( $\left.\mathrm{CR}_{\mathrm{MRD}}\right)$ as the primary endpoint of their study (130-137). Recently, Tiong and colleagues published a retrospective study about venetoclax that could make patients with low-intensity chemotherapy achieve durable $\mathrm{CR}_{\text {mrd }}$ status (138). The change in MRD levels (139-143) or the proportion of patients achieving MRD negativity (144-149) are also frequent primary endpoints of studies. Furthermore, trials that use MRD as primary endpoint are frequently trials with unfit patients and relapsed/refractory patients $(130,131,134,135,137,142,146,148)$. 
TABLE 3 | Current trials using MRD as a primary endpoint.

\begin{tabular}{|c|c|c|c|c|c|c|c|}
\hline & Clinicaltrials.gov & Phase & $\mathbf{n}$ & Age & Treatment & Group & Technique \\
\hline \multicolumn{8}{|l|}{$\begin{array}{l}\text { Groups primary } \\
\text { endpoints }\end{array}$} \\
\hline \multirow[t]{9}{*}{$\mathrm{CR}_{\text {mrd }}$} & NCT04284787 & $\|$ & 76 & $>60$ & $\begin{array}{l}\text { Pembrolizumab, Azacitidine, } \\
\text { venetoclax }\end{array}$ & Unfit & $\begin{array}{l}\text { Duplex sequencing, } \\
\text { MFC }\end{array}$ \\
\hline & NCT03150004 & $\|$ & 90 & $>18$ & CLAG-M & R/R secondary AML & MFC \\
\hline & NCT04476199 & $\|$ & 100 & $60-75$ & Venetoclax, decitabine & De novo, alloSCT & $\begin{array}{l}\text { MFC, cytogenetics, } \\
\text { RT-qPCR }\end{array}$ \\
\hline & NCT03573024 & $\|$ & 36 & $18-59$ & Venetoclax, azacitidine & De novo & MFC \\
\hline & NCT03701295 & $1 / I I$ & 36 & $>18$ & Pinometostat, azacitidine & $11 q 23$ & Unknown \\
\hline & NCT03654703 & $\|$ & 100 & $3-18$ & Cyclophasphamide regimens & Pediatric R/R & MFC \\
\hline & NCT01831232 & NA & 24 & $18-74$ & $\begin{array}{l}\text { Idarubicin, cytarabine, } \\
\text { pravastatin sodium }\end{array}$ & De novo AML MDS & MFC \\
\hline & NCT04196010 & I & 45 & $>18$ & Cl-CLAM & $\begin{array}{l}\text { AML } r / r \text { or other high-grade myeloid } \\
\text { neoplasms }\end{array}$ & Unknown \\
\hline & NCT04214249 & $\|$ & 124 & $>18$ & $\begin{array}{l}\text { Pembrolizumab + intensive } \\
\text { chemotherapy }\end{array}$ & De novo & MFC \\
\hline $\begin{array}{l}\text { Proportion MRD } \\
\text { negativity/ }\end{array}$ & NCT04168502 & III & 414 & $18-60$ & Gemtuzumab, glasdegib & $\begin{array}{l}\text { De novo, favorable } \\
\text { intermediate risk }\end{array}$ & Unknown \\
\hline \multirow[t]{5}{*}{ positivity } & NCT04093505 & III & 252 & $>60$ & GO, glasdegib & De novo, post remission & MFC \\
\hline & NCT04000698 & $|/| \mid$ & 25 & $<25$ & Different targeted therapies & Pediatric R/R & Unknown \\
\hline & NCT03699384 & $|/| \mid$ & 0 & $>18$ & Azacitidine Avelumab & MRD positive & MFC \\
\hline & NCT02614560 & $1 / 11$ & 14 & $18-75$ & Vadastuximab Talirine & $\mathrm{R} / \mathrm{R} \mathrm{AML}$ & Unknown \\
\hline & NCT04347616 & $|/| \mid$ & 24 & $>18$ & NK cell therapy & $\mathrm{R} / \mathrm{R} \mathrm{AML}$ & MFC/PCR \\
\hline MRD change/ & NCT03737955 & $\|$ & 36 & $>2$ & $\mathrm{GO}$ & MRD positive + prior treatment & MFC/PCR \\
\hline \multirow[t]{4}{*}{ conversion } & NCT01677949 & $\|$ & 0 & $<60$ & $\begin{array}{l}\text { Clofarabine, } \\
\text { cyclophosphamide, etoposide }\end{array}$ & $\mathrm{ALL}, \mathrm{AML}$ & MFC/PCR \\
\hline & NCT00863434 & $\|$ & 2 & $18-75$ & Clofarabine, Cytarabine & MRD positive & MFC \\
\hline & NCT03697707 & $\|$ & 20 & $>18$ & Dendritic cell therapy & R/R AML persistent MRD & MFC \\
\hline & NCT03021395 & $|/| \mid$ & 300 & $14-55$ & Decitabine & After consolidation & Unknown \\
\hline \multirow[t]{6}{*}{ MRD not specified } & NCT04209712 & $\begin{array}{l}\text { Early } \\
\text { phase I }\end{array}$ & 6 & $1-80$ & NK infusion & $\begin{array}{l}\text { MRD positive, after two cycles } \\
\text { chemotherapy and no SCT }\end{array}$ & MFC \\
\hline & NCT01828489 & III & 300 & $0-80$ & $\begin{array}{l}\text { Cytarabine/fludarabine, } \\
\text { DaunoXome, etoposide/ } \\
\text { cytarabine }\end{array}$ & Children/adolescents & MFC \\
\hline & NCT00965224 & $\|$ & 50 & $>18$ & Dendritic cell therapy & Myeloid leukemia and Myeloma & WT1 PCR \\
\hline & NCT04086264 & $|/| \mid$ & 212 & $18-120$ & $\begin{array}{l}\text { IMGN632, venetoclax, } \\
\text { Azacitidine }\end{array}$ & CD123 positive AML & MFC \\
\hline & NCT01347996 & IV & 84 & $>18$ & Histamine, IL-2 & $\mathrm{AML}$ in $\mathrm{CR} 1$ & RQ-PCR \\
\hline & NCT03665480 & $\|/ I\|$ & 122 & $14-65$ & G-CSF & De novo & Unknown \\
\hline
\end{tabular}

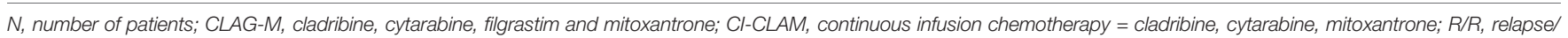

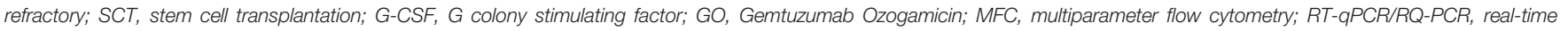
quantitative polymerase chain reaction.

For the use of MRD as a surrogate endpoint, the document provided by the FDA (36) stated that: "The strength for a potential surrogate endpoint relies on the biological plausibility of the relationship, demonstration in epidemiological studies of the prognostic value of the surrogate endpoint for the clinical outcome and evidence from clinical trials that treatment effects on the surrogate endpoint correspond to effects on the clinical outcome".

For MRD, both the biological plausibility of the relationship that MRD initiates relapse and its relation to OS and the prognostic value of MRD are published and generally accepted. Clinical trials which show clear and significant additional effect of the new treatment and also include MRD are scarce but instrumental for qualifying MRD as a surrogate endpoint. Whether MRD as surrogate endpoint eventually includes the difference or decrease in MRD level, frequency of converted MRD positive patients, or frequency of MRD negative patients remains to be investigated and is an attractive emerging research field in the upcoming years (150-152).

\section{Prediction Models for Improved Personalized Medicine}

As previously stated, MRD is valuable to stratify patients according on the risk of relapse; however, $30 \%$ of MRD negative patients still relapse. Hence, based on its sensitivity and specificity measures, MRD is not yet predictive for the individual patient $(3,44)$. For achieving a better prediction, state-of-the-art techniques may help in further characterization of different AML subtypes. For the development of the right prediction models, there are several scoring systems to estimate mortality in different subgroups of AML [reviewed by Walter 


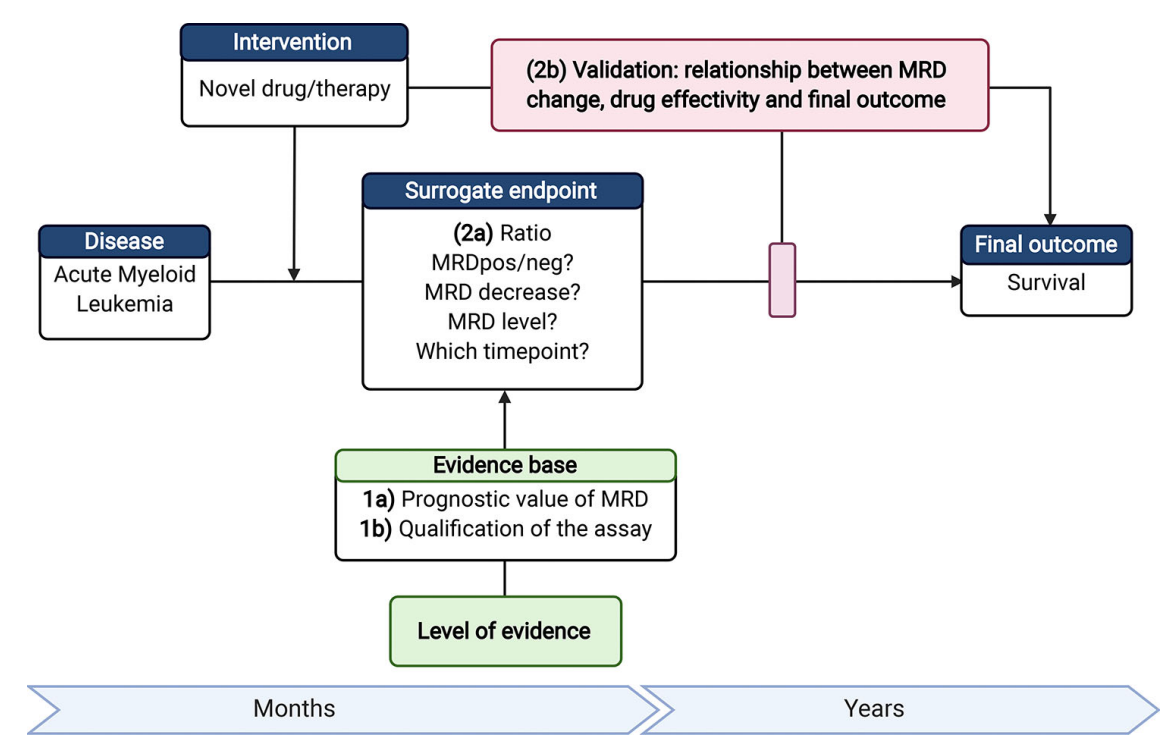

FIGURE 3 | Requirements to make MRD eligible as a surrogate endpoint. 1a) Next to the current evidence on the prognostic value of MRD; 1b) the MRD assay should be qualified (accurate MRD measurements with established lower limit of quantification). 2a) For use of MRD as surrogate endpoint, the time point of MRD assessment and readout measures, such as threshold of MRD-positivity or level of decrease (log-reduction), should be established; 2b) Ultimately, it is required to validate the association between treatment effectivity, MRD as surrogate endpoint, and the change in outcome. Therefore, the added value of MRD as surrogate endpoint has to be shown in a clinical trial with a (novel) treatment that gives a significant survival benefit and a significant change in MRD using the selected readout 2a). AML, Acute Myeloid Leukemia; MFC, multiparameter flow cytometry; MRD, Measurable residual disease. Created with BioRender.com.

and Estey (153)]. However, data is not yet collected systematically and presented clearly, which makes it unclear how and when to use MRD in the individual patient with specific characteristics. As described by Walter and Estey, data of these prediction models should also be updated frequently to assure the accuracy of the model (153).

In the future, applications or websites that calculate the individual risk of a relapse or survival based on treatment choice may play a larger role in supporting clinical decision making in AML. A good prediction model is needed to support this application (154). By using a multistage model for predicting outcome, genomic and clinical variables in AML, Gerstung and colleagues were capable of making an application that determines individual risk for each specific treatment choice (155). To make a prediction model that calculates the individual prognosis, fully annotated individual patient data and large datasets are needed (155). However, combining datasets are time-consuming and challenging due to technical differences of the specific MRD technique, annotations, and different database source programs used in different institutes. Standardization and harmonization of MRD measurement techniques should also improve the comparability of MRD results in the future. Furthermore, forming regulations and reaching agreements between collaborative parties to ensure safe data transfer can also be challenging and time-consuming due differences in legislation. Currently, the HARMONY alliance big data portal is in development to combine survival data from different hematological diseases (156). Another initiative to combine MRD data is from the collaborators of the AML MRD working party of the European Leukemia Net, where MRD data of many different studies will be collected in the upcoming years.
These advances in the harmonization of MRD assessments to be used in big data analyses are essential to achieve an application to guide clinicians and patients in their clinical decision makings based on accurate relapse risk predictions.

\section{DISCUSSION}

MRD is quickly evolving in terms of the biological, technical, and clinical research fields. The use of MRD is potentially relevant for several clinical decisions such as MRD tailored therapy (before and after transplant) and as a surrogate endpoint to push forward the therapeutic AML landscape. However, to make the MRD assessment good enough for all these envisioned purposes, technical features of the MRD assay should be standardized, harmonized, and validated in prospective trials. Several considerations arise in incorporating MRD tailored therapy, such as taking into account which treatment (intensive $v s$. non-intensive or chemotherapy $v s$. targeted), time point during therapy, use of MRD technique, selected threshold per time point, usage of BM or $\mathrm{PB}$, and possibly also the kinetics of MRD clearance in different AML subtypes. To evaluate MRD as a surrogate marker, MRD should be incorporated in more clinical trial designs. Furthermore, clinical data should be as complete as possible for all relevant prognostic markers to increase the predictive value of models, including (LSC)-MRD and precision medicine.

With all these considerations, MRD is indispensable from the treatment of AML. What we have learned so far about MRD tailored therapy is that the clinical practice is eagerly anticipating the use of MRD for clinical decision making. However, the use of 
the current assays for accurate risk prediction for the individual patient needs more careful evaluation. To reach that goal, data science and meta-analysis of large clinical trial with MRD data are being employed to improve personalized treatment and outcome for the individual patient.

\section{REFERENCES}

1. Vosberg S, Greif PA. Clonal evolution of acute myeloid leukemia from diagnosis to relapse. Genes Chromosomes Cancer (2019) 58(12):839-49. doi: $10.1002 /$ gcc. 22806

2. Siegel RL, Miller KD, Jemal A. Cancer statistics, 2020. CA Cancer J Clin (2020) 70(1):7-30. doi: 10.3322/caac.21590

3. Terwijn M, van Putten WL, Kelder A, van der Velden VH, Brooimans RA, Pabst $\mathrm{T}$, et al. High prognostic impact of flow cytometric minimal residual disease detection in acute myeloid leukemia: data from the HOVON/SAKK AML 42A study. J Clin Oncol (2013) 31(31):3889-97. doi: 10.1200/jco.2012.45.9628

4. Al-Mawali A, Gillis D, Hissaria P, Lewis I. Incidence, sensitivity, and specificity of leukemia-associated phenotypes in acute myeloid leukemia using specific five-color multiparameter flow cytometry. Am J Clin Pathol (2008) 129(6):934-45. doi: 10.1309/FY0UMAMM91VPMR2W

5. Hourigan CS, Karp JE. Minimal residual disease in acute myeloid leukaemia. Nat Rev Clin Oncol (2013) 10(8):460-71. doi: 10.1038/nrclinonc.2013.100

6. Freireich EJ, Cork A, Stass SA, McCredie KB, Keating MJ, Estey EH, et al. Cytogenetics for detection of minimal residual disease in acute myeloblastic leukemia. Leukemia (1992) 6(6):500-6.

7. Fröhling S, Skelin S, Liebisch C, Scholl C, Schlenk RF, Döhner H, et al. Comparison of cytogenetic and molecular cytogenetic detection of chromosome abnormalities in 240 consecutive adult patients with acute myeloid leukemia. J Clin Oncol (2002) 20(10):2480-5. doi: 10.1200/JCO.2002.08.155

8. Ossenkoppele G, Schuurhuis GJ. MRD in AML: does it already guide therapy decision-making? Hematol Am Soc Hematol Educ Program (2016) 2016(1):356-65. doi: 10.1182/asheducation-2016.1.356

9. Falini B, Mecucci C, Tiacci E, Alcalay M, Rosati R, Pasqualucci L, et al. Cytoplasmic Nucleophosmin in Acute Myelogenous Leukemia with a Normal Karyotype. N Engl J Med (2005) 352(3):254-66. doi: 10.1056/ NEJMoa041974

10. Schnittger S, Kern W, Tschulik C, Weiss T, Dicker F, Falini B, et al. Minimal residual disease levels assessed by NPM1 mutation-specific RQ-PCR provide important prognostic information in AML. Blood (2009) 114(11):2220-31. doi: 10.1182/blood-2009-03-213389

11. Young AL, Challen GA, Birmann BM, Druley TE. Clonal haematopoiesis harbouring AML-associated mutations is ubiquitous in healthy adults. Nat Commun (2016) 7:12484. doi: 10.1038/ncomms 12484

12. Zhou Y, Wood BL. Methods of Detection of Measurable Residual Disease in AML. Curr Hematol Malig Rep (2017) 12(6):557-67. doi: 10.1007/s11899017-0419-5

13. Jentzsch M, Schwind S, Bach E, Stasik S, Thiede C, Platzbecker U. Clinical Challenges and Consequences of Measurable Residual Disease in Non-APL Acute Myeloid Leukemia. Cancers (2019) 11(11). doi: 10.3390/cancers11111625

14. Hanekamp D, Bachas C, van de Loosdrecht A, Ossenkoppele G, Cloos J. Re: Myeloblasts in normal bone marrows expressing leukaemia-associated immunophenotypes. Pathology (2020) 52(2):289-91. doi: 10.1016/ j.pathol.2019.09.021

15. Wood BL. Acute Myeloid Leukemia Minimal Residual Disease Detection: The Difference from Normal Approach. Curr Protoc Cytom (2020) 93(1): e73. doi: $10.1002 /$ cpcy.73

16. Sui JN, Chen QS, Zhang YX, Sheng Y, Wu J, Li JM, et al. Identifying leukemia-associated immunophenotype-based individualized minimal residual disease in acute myeloid leukemia and its prognostic significance. Am J Hematol (2019) 94(5):528-38. doi: 10.1002/ ajh. 25431

17. Rossi G, Giambra V, Minervini MM, De Waure C, Mancinelli S, Ciavarella M, et al. Leukemia-associated immunophenotypes subdivided in "categories of specificity" improve the sensitivity of minimal residual disease in predicting

\section{AUTHOR CONTRIBUTIONS}

LN wrote the manuscript, which was further revised by AK, JJ, GO, and JC. All authors contributed to the article and approved the submitted version.

relapse in acute myeloid leukemia. Cytometry Part B Clin Cytom (2020) 98 (3):216-25. doi: 10.1002/cyto.b.21855

18. Freeman SD, Hills RK, Virgo P, Khan N, Couzens S, Dillon R, et al. Measurable Residual Disease at Induction Redefines Partial Response in Acute Myeloid Leukemia and Stratifies Outcomes in Patients at Standard Risk Without NPM1 Mutations. J Clin Oncol (2018) 36(15):1486-97. doi: 10.1200/JCO.2017.76.3425

19. Zhou Y, Moon A, Hoyle E, Fromm JR, Chen X, Soma L, et al. Pattern associated leukemia immunophenotypes and measurable disease detection in acute myeloid leukemia or myelodysplastic syndrome with mutated NPM1. Cytometry Part B Clin Cytom (2019) 96(1):67-72. doi: 10.1002/cyto.b.21744

20. He SZ, Busfield S, Ritchie DS, Hertzberg MS, Durrant S, Lewis ID, et al. A Phase 1 study of the safety, pharmacokinetics and anti-leukemic activity of the anti-CD123 monoclonal antibody CSL360 in relapsed, refractory or high-risk acute myeloid leukemia. Leuk Lymphoma (2015) 56(5):1406-15. doi: $10.3109 / 10428194.2014 .956316$

21. van Loo PF, Hangalapura BN, Thordardottir S, Gibbins JD, Veninga H, Hendriks LJA, et al. MCLA-117, a CLEC12AxCD3 bispecific antibody targeting a leukaemic stem cell antigen, induces $\mathrm{T}$ cell-mediated AML blast lysis. Expert Opin Biol Ther (2019) 19(7):721-33. doi: 10.1080/ 14712598.2019.1623200

22. Ivey A, Hills RK, Simpson MA, Jovanovic JV, Gilkes A, Grech A, et al. Assessment of Minimal Residual Disease in Standard-Risk AML. N Engl J Med (2016) 374(5):422-33. doi: 10.1056/NEJMoa1507471

23. Rucker FG, Agrawal M, Corbacioglu A, Weber D, Kapp-Schwoerer S, Gaidzik VI, et al. Measurable residual disease monitoring in acute myeloid leukemia with $\mathrm{t}()(\mathrm{q} 22 ; \mathrm{q} 22.1)$ : results from the AML Study Group. Blood (2019) 134(19):1608-18. doi: 10.1182/blood.2019001425

24. Bachas C, Schuurhuis GJ, Hollink IH, Kwidama ZJ, Goemans BF, Zwaan $\mathrm{CM}$, et al. High-frequency type I/II mutational shifts between diagnosis and relapse are associated with outcome in pediatric AML: implications for personalized medicine. Blood (2010) 116(15):2752-8. doi: 10.1182/blood2010-03-276519

25. Nazha A, Cortes J, Faderl S, Pierce S, Daver N, Kadia T, et al. Activating internal tandem duplication mutations of the fms-like tyrosine kinase-3 (FLT3-ITD) at complete response and relapse in patients with acute myeloid leukemia. Haematologica (2012) 97(8):1242-5. doi: 10.3324/haematol. 2012.062638

26. Helbig G, Koclega A, Wieczorkiewicz-Kabut A, Wozniczka K, Kopinska A, Boral K, et al. Pre-transplant FLT3/ITD status predicts outcome in FLT3mutated acute myeloid leukemia following allogeneic stem cell transplantation. Ann Hematol (2020) 99(8):1845-53. doi: 10.1007/s00277-020-04026-1

27. Allen C, Hills RK, Lamb K, Evans C, Tinsley S, Sellar R, et al. The importance of relative mutant level for evaluating impact on outcome of KIT, FLT3 and CBL mutations in core-binding factor acute myeloid leukemia. Leukemia (2013) 27(9):1891-901. doi: 10.1038/leu.2013.186

28. Schiller J, Praulich I, Krings Rocha C, Kreuzer KA. Patient-specific analysis of FLT3 internal tandem duplications for the prognostication and monitoring of acute myeloid leukemia. Eur J Haematol (2012) 89(1):5362. doi: 10.1111/j.1600-0609.2012.01785.x

29. Bullinger L, Dohner K, Dohner H. Genomics of Acute Myeloid Leukemia Diagnosis and Pathways. J Clin Oncol (2017) 35(9):934-46. doi: 10.1200/ JCO.2016.71.2208

30. De Marchi F, Candoni A, Zannier ME, Haley L, Lau BW, Fanin R. Concomitant monitoring of WT1 and FLT3-ITD expression in FLT3-ITD acute myeloid leukemia patients: which should we trust as a minimal residual disease marker? Am J Hematol (2017) 92(5):E72-e4. doi: 10.1002/ajh.24686

31. Rautenberg C, Bergmann A, Pechtel S, Fischermanns C, Haas R, Germing U, et al. Wilm's Tumor 1-guided preemptive treatment with hypomethylating 
agents for molecular relapse of AML and MDS after allogeneic transplantation. Bone Marrow Transplant (2020). doi: 10.1038/s41409-020-01039-2

32. Luo P, Jing W, Yi K, Wu S, Zhou F. Wilms' tumor 1 gene in hematopoietic malignancies: clinical implications and future directions. Leuk Lymphoma (2020) 61(9):2059-67. doi: 10.1080/10428194.2020.1762884

33. Brooimans RA, van der Velden VHJ, Boeckx N, Slomp J, Preijers F, Te Marvelde JG, et al. Immunophenotypic measurable residual disease (MRD) in acute myeloid leukemia: Is multicentric MRD assessment feasible? Leuk Res (2019) 76:39-47. doi: 10.1016/j.leukres.2018.11.014

34. Zeijlemaker W, Kelder A, Cloos J, Schuurhuis GJ. Immunophenotypic Detection of Measurable Residual (Stem Cell) Disease Using LAIP Approach in Acute Myeloid Leukemia. Curr Protoc Cytom (2019) 91(1): e66. doi: 10.1002/cpcy.66

35. Cloos J, Harris JR, Janssen J, Kelder A, Huang F, Sijm G, et al. Comprehensive Protocol to Sample and Process Bone Marrow for Measuring Measurable Residual Disease and Leukemic Stem Cells in Acute Myeloid Leukemia. J Vis Exp (2018) 5(133):56386. doi: 10.3791/56386

36. U.S. Department of Health and Human Services, Oncology Center of Excellence, Center for Drug Evaluation and Research, Center for Biologics Evaluation and Research. Hematologic Malignancies: Regulatory Considerations for Use of Minimal Residual Disease in Development of Drug and Biological Products for Treatment. Food and Drug Administration (2020) FDA-2018-D-3090. Available from: https://www.fda.gov/media/134605/download; https://www.fda.gov/ regulatory-information/search-fda-guidance-documents/hematologicmalignancies-regulatory-considerations-use-minimal-residual-diseasedevelopment-drug-and

37. Wood B, Jevremovic D, Béné MC, Yan M, Jacobs P, Litwin V, et al. Validation of cell-based fluorescence assays: Practice guidelines from the ICSH and ICCS - part V - assay performance criteria. Cytometry Part B Clin Cytom (2013) 84(5):315-23. doi: 10.1002/cyto.b.21108

38. Schuurhuis GJ, Heuser M, Freeman S, Bene MC, Buccisano F, Cloos J, et al. Minimal/measurable residual disease in AML: a consensus document from the European LeukemiaNet MRD Working Party. Blood (2018) 131 (12):1275-91. doi: 10.1182/blood-2017-09-801498

39. Hope KJ, Jin L, Dick JE. Acute myeloid leukemia originates from a hierarchy of leukemic stem cell classes that differ in self-renewal capacity. Nat Immunol (2004) 5(7):738-43. doi: 10.1038/ni1080

40. Bonnet D, Dick JE. Human acute myeloid leukemia is organized as a hierarchy that originates from a primitive hematopoietic cell. Nat Med (1997) 3(7):730-7. doi: 10.1038/nm0797-730

41. Becker MW, Jordan CT. Leukemia stem cells in 2010: Current understanding and future directions. Blood Rev (2011) 25(2):75-81. doi: 10.1016/j.blre.2010.11.001

42. van Rhenen A, Feller N, Kelder A, Westra AH, Rombouts E, Zweegman S, et al. High stem cell frequency in acute myeloid leukemia at diagnosis predicts high minimal residual disease and poor survival. Clin Cancer Res (2005) 11(18):6520-7. doi: 10.1158/1078-0432.CCR-05-0468

43. Zeijlemaker W, Kelder A, Oussoren-Brockhoff YJ, Scholten WJ, Snel AN, Veldhuizen D, et al. A simple one-tube assay for immunophenotypical quantification of leukemic stem cells in acute myeloid leukemia. Leukemia (2016) 30(2):439-46. doi: 10.1038/leu.2015.252

44. Zeijlemaker W, Grob T, Meijer R, Hanekamp D, Kelder A, Carbaat-Ham JC, et al. CD34(+)CD38(-) leukemic stem cell frequency to predict outcome in acute myeloid leukemia. Leukemia (2019) 33(5):1102-12. doi: 10.1038/ s41375-018-0326-3

45. Plesa A, Dumontet C, Mattei E, Tagoug I, Hayette S, Sujobert P, et al. High frequency of CD34+CD38-/low immature leukemia cells is correlated with unfavorable prognosis in acute myeloid leukemia. World J Stem Cells (2017) 9(12):227-34. doi: 10.4252/wjsc.v9.i12.227

46. Kandeel EZ, El Sharkawy N, Hanafi M, Samra M, Kamel A. Tracing Leukemia Stem Cells and Their Influence on Clinical Course of Adult Acute Myeloid Leukemia. Clin Lymphoma myeloma Leuk (2020) 20(6):38393. doi: 10.1016/j.clml.2019.11.018

47. Buccisano F, Palmieri R, Irno Consalvo M, Piciocchi A, Maurillo L, Del Principe MI, et al. Leukemic Stem Cells Persistence Measured By Multiparametric Flow Cytometry Is a Biomarker of Poor Prognosis in Adult Patients with Acute Myeloid Leukemia. Blood (2019) 134 (Supplement_1):2688-. doi: 10.1182/blood-2019-128025
48. Almohsen F, Al-Mudallal SS. Impact of Leukemia Stem Cells Phenotype Expression on Response to Induction Therapy in Acute Myeloid Leukemia Patients. Cardiovasc Hematol Disord Drug Targets (2020) 20(2):145-51. doi: 10.2174/1871529X19666190719105954

49. Hanekamp D, Denys B, Kaspers GJL, Te Marvelde JG, Schuurhuis GJ, De Haas V, et al. Leukaemic stem cell load at diagnosis predicts the development of relapse in young acute myeloid leukaemia patients. Br J Haematol (2018) 183(3):512-6. doi: 10.1111/bjh.14991

50. Hanekamp D, Snel AN, Kelder A, Scholten WJ, Khan N, Metzner M, et al. Applicability and reproducibility of acute myeloid leukaemia stem cell assessment in a multi-centre setting. Br J Haematol (2020) 190(6):891900. doi: 10.1111/bjh.16594

51. Freeman SD, Hourigan CS. MRD evaluation of AML in clinical practice: are we there yet? Hematol Am Soc Hematol Educ Program (2019) 2019(1):55769. doi: 10.1182/hematology.2019000060

52. Eppert K, Takenaka K, Lechman ER, Waldron L, Nilsson B, van Galen P, et al. Stem cell gene expression programs influence clinical outcome in human leukemia. Nat Med (2011) 17(9):1086-93. doi: 10.1038/nm.2415

53. Hanekamp D, Cloos J, Schuurhuis GJ. Leukemic stem cells: identification and clinical application. Int J Hematol (2017) 105(5):549-57. doi: 10.1007/ s12185-017-2221-5

54. Zeijlemaker W, Kelder A, Oussoren-Brockhoff YJM, Scholten WJ, Snel AN, Veldhuizen D, et al. A simple one-tube assay for immunophenotypical quantification of leukemic stem cells in acute myeloid leukemia. Leukemia (2016) 30(2):439-46. doi: 10.1038/leu.2015.252

55. Daga S, Rosenberger A, Quehenberger F, Krisper N, Prietl B, Reinisch A, et al. High GPR56 surface expression correlates with a leukemic stem cell gene signature in CD34-positive AML. Cancer Med (2019) 8(4):1771-8. doi: $10.1002 / \mathrm{cam} 4.2053$

56. Yabushita T, Satake H, Maruoka H, Morita M, Katoh D, Shimomura Y, et al. Expression of multiple leukemic stem cell markers is associated with poor prognosis in de novo acute myeloid leukemia. Leuk Lymphoma (2018) 59 (9):2144-51. doi: 10.1080/10428194.2017.1410888

57. Niewold P, Ashhurst TM, Smith AL, King NJC. Evaluating spectral cytometry for immune profiling in viral disease. Cytometry A (2020) 97 (11):1165-79. doi: 10.1002/cyto.a.24211

58. Ferret Y, Boissel N, Helevaut N, Madic J, Nibourel O, Marceau-Renaut A, et al. Clinical relevance of IDH1/2 mutant allele burden during follow-up in acute myeloid leukemia. A study by the French ALFA group. Haematologica (2018) 103(5):822-9. doi: 10.3324/haematol.2017. 183525

59. Bill M, Grimm J, Jentzsch M, Kloss L, Goldmann K, Schulz J, et al Digital droplet PCR-based absolute quantification of pre-transplant NPM1 mutation burden predicts relapse in acute myeloid leukemia patients. Ann Hematol (2018) 97(10):1757-65. doi: 10.1007/s00277-0183373-y

60. Winters A, Goosman M, Stevens BM, Purev E, Smith C, Pollyea DA, et al. Tracking of AML-Associated Mutations Via Droplet Digital PCR Is Predictive of Outcomes Post-Transplant. Blood (2018) 132(Supplement 1):2138-. doi: 10.1182/blood-2018-99-110834

61. Grassi S, Guerrini F, Ciabatti E, Puccetti R, Salehzadeh S, Metelli MR, et al Digital Droplet PCR is a Specific and Sensitive Tool for Detecting IDH2 Mutations in Acute Myeloid LeuKemia Patients. Cancers (2020) 12(7):1738. doi: $10.3390 /$ cancers 12071738

62. Levine RL, Valk PJM. Next-generation sequencing in the diagnosis and minimal residual disease assessment of acute myeloid leukemia Haematologica (2019) 104(5):868-71. doi: 10.3324/haematol.2018.205955

63. Thol F, Gabdoulline R, Liebich A, Klement P, Schiller J, Kandziora C, et al. Measurable residual disease monitoring by NGS before allogeneic hematopoietic cell transplantation in AML. Blood (2018) 132(16):1703-13. doi: 10.1182/blood-2018-02-829911

64. Hourigan CS, Dillon LW, Gui G, Logan BR, Fei M, Ghannam J, et al. Impact of Conditioning Intensity of Allogeneic Transplantation for Acute Myeloid Leukemia With Genomic Evidence of Residual Disease. J Clin Oncol (2020) 38(12):1273-83. doi: 10.1200/JCO.19.03011

65. Yoest JM, Shirai CL, Duncavage EJ. Sequencing-Based Measurable Residual Disease Testing in Acute Myeloid Leukemia. Front Cell Dev Biol (2020) 8:249. doi: $10.3389 /$ fcell.2020.00249 
66. Ghannam J, Dillon LW, Hourigan CS. Next-generation sequencing for measurable residual disease detection in acute myeloid leukaemia. $\mathrm{Br} \mathrm{J}$ Haematol (2020) 188(1):77-85. doi: 10.1111/bjh.16362

67. Salk JJ, Schmitt MW, Loeb LA. Enhancing the accuracy of next-generation sequencing for detecting rare and subclonal mutations. Nat Rev Genet (2018) 19(5):269-85. doi: 10.1038/nrg.2017.117

68. Hoermann G, Greiner G, Griesmacher A, Valent P. Clonal Hematopoiesis of Indeterminate Potential: A Multidisciplinary Challenge in Personalized Hematology. J Pers Med (2020) 10(3). doi: 10.3390/jpm10030094

69. Jongen-Lavrencic M, Grob T, Hanekamp D, Kavelaars FG, Al Hinai A, Zeilemaker A, et al. Molecular Minimal Residual Disease in Acute Myeloid Leukemia. N Engl J Med (2018) 378(13):1189-99. doi: 10.1056/ NEJMoa1716863

70. Venditti A, Piciocchi A, Candoni A, Melillo L, Calafiore V, Cairoli R, et al. GIMEMA AML1310 trial of risk-adapted, MRD-directed therapy for young adults with newly diagnosed acute myeloid leukemia. Blood (2019) 134 (12):935-45. doi: 10.1182/blood.2018886960

71. Morita K, Kantarjian HM, Wang F, Yan Y, Bueso-Ramos C, Sasaki K, et al. Clearance of Somatic Mutations at Remission and the Risk of Relapse in Acute Myeloid Leukemia. J Clin Oncol (2018) 36(18):1788-97. doi: 10.1200/ JCO.2017.77.6757

72. Fang M, Storer B, Wood B, Gyurkocza B, Sandmaier BM, Appelbaum FR. Prognostic impact of discordant results from cytogenetics and flow cytometry in patients with acute myeloid leukemia undergoing hematopoietic cell transplantation. Cancer (2012) 118(9):2411-9. doi: 10.1002/cncr.26539

73. Getta BM, Devlin SM, Levine RL, Arcila ME, Mohanty AS, Zehir A, et al. Multicolor Flow Cytometry and Multigene Next-Generation Sequencing Are Complementary and Highly Predictive for Relapse in Acute Myeloid Leukemia after Allogeneic Transplantation. Biol Blood Marrow Transplant (2017) 23(7):1064-71. doi: 10.1016/j.bbmt.2017.03.017

74. Ossenkoppele GJ, Schuurhuis GJ. MRD in AML: it is time to change the definition of remission. Best Pract Res Clin Haematol (2014) 27(3-4):265-71. doi: 10.1016/j.beha.2014.10.008

75. Dohner H, Estey E, Grimwade D, Amadori S, Appelbaum FR, Buchner T, et al. Diagnosis and management of AML in adults: 2017 ELN recommendations from an international expert panel. Blood (2017) 129 (4):424-47. doi: 10.1182/blood-2016-08-733196

76. Wang Z, Guo M, Zhang Y, Xu S, Cheng H, Wu J, et al. The applicability of multiparameter flow cytometry for the detection of minimal residual disease using different-from-normal panels to predict relapse in patients with acute myeloid leukemia after allogeneic transplantation. Int J Lab Hematol (2019) 41(5):607-14. doi: 10.1111/ijlh.13070

77. Tan Y, Fu Y, Liu C, Sun J, Liu S, Lin H, et al. Minimal residual disease may be an early prognostic indicator for newly diagnosed acute myeloid leukemia patients induced by decitabine-based chemotherapy. Hematol (Amsterdam Netherlands) (2019) 24(1):552-8. doi: 10.1080/16078454.2019.1642552

78. Press RD, Eickelberg G, Froman A, Yang F, Stentz A, Flatley EM, et al. Nextgeneration sequencing-defined minimal residual disease before stem cell transplantation predicts acute myeloid leukemia relapse. Am J Hematol (2019) 94(8):902-12. doi: 10.1002/ajh.25514

79. Patkar N, Kakirde C, Bhanshe P, Joshi S, Chaudhary S, Badrinath Y, et al. Utility of Immunophenotypic Measurable Residual Disease in Adult Acute Myeloid Leukemia-Real-World Context. Front Oncol (2019) 9:450. doi: $10.3389 /$ fonc. 2019.00450

80. Minetto P, Guolo F, Clavio M, Kunkl A, Colombo N, Carminati E, et al. Early minimal residual disease assessment after AML induction with fludarabine, cytarabine and idarubicin (FLAI) provides the most useful prognostic information. Br J Haematol (2019) 184(3):457-60. doi: 10.1111/ bjh.15106

81. Walter RB, Pagel JM, Gooley TA, Petersdorf EW, Sorror ML, Woolfrey AE, et al. Comparison of matched unrelated and matched related donor myeloablative hematopoietic cell transplantation for adults with acute myeloid leukemia in first remission. Leukemia (2010) 24(7):1276-82. doi: 10.1038/leu.2010.102

82. Hoffmann AP, Besch AL, Othus M, Morsink LM, Wood BL, Mielcarek M, et al. Early achievement of measurable residual disease (MRD)-negative complete remission as predictor of outcome after myeloablative allogeneic hematopoietic cell transplantation in acute myeloid leukemia. Bone Marrow Transplant (2020) 55(3):669-72. doi: 10.1038/s41409-019-0739-2

83. Liu J, Ma R, Liu YR, Xu LP, Zhang XH, Chen H, et al. The significance of peri-transplantation minimal residual disease assessed by multiparameter flow cytometry on outcomes for adult AML patients receiving haploidentical allografts. Bone Marrow Transplant (2019) 54(4):567-77. doi: 10.1038/ s41409-018-0300-8

84. Shah MV, Jorgensen JL, Saliba RM, Wang SA, Alousi AM, Andersson BS, et al. Early Post-Transplant Minimal Residual Disease Assessment Improves Risk Stratification in Acute Myeloid Leukemia. Biol Blood Marrow Transplant (2018) 24(7):1514-20. doi: 10.1016/j.bbmt.2018.02.003

85. Epstein-Peterson ZD, Devlin SM, Stein EM, Estey E, Tallman MS. Widespread use of measurable residual disease in acute myeloid leukemia practice. Leuk Res (2018) 67:92-8. doi: 10.1016/j.leukres.2018.02.006

86. Zhu HH, Zhang XH, Qin YZ, Liu DH, Jiang H, Chen H, et al. MRD-directed risk stratification treatment may improve outcomes of $\mathrm{t}($ ) AML in the first complete remission: results from the AML05 multicenter trial. Blood (2013) 121(20):4056-62. doi: 10.1182/blood-2012-11-468348

87. Platzbecker U, Middeke JM, Sockel K, Herbst R, Wolf D, Baldus CD, et al. Measurable residual disease-guided treatment with azacitidine to prevent haematological relapse in patients with myelodysplastic syndrome and acute myeloid leukaemia (RELAZA2): an open-label, multicentre, phase 2 trial. Lancet Oncol (2018) 19(12):1668-79. doi: 10.1016/S1470-2045 (18)30580-1

88. Todisco E, Gigli F, Sammassimo S, Camisaschi C, Mancuso P, Ronchini C, et al. Efficacy of venetoclax based salvage chemotherapy followed by "Minimal Residual Disease driven"-venetoclax maintenance therapy postallotransplant in a young patient with high risk primary refractory acute myeloid leukemia. Leuk Lymphoma (2020) 61(9):2277-9. doi: 10.1080/ 10428194.2020.1759049s

89. Versluis J, Kalin B, Zeijlemaker W, Passweg J, Graux C, Manz MG, et al. Graft-Versus-Leukemia Effect of Allogeneic Stem-Cell Transplantation and Minimal Residual Disease in Patients With Acute Myeloid Leukemia in First Complete Remission. JCO Precis Oncol (2017) 1(1):1-13. doi: 10.1200/ PO.17.00078

90. Versluis J, Cornelissen JJ. Risks and benefits in a personalized application of allogeneic transplantation in patients with AML in first CR. Semin Hematol (2019) 56(2):164-70. doi: 10.1053/j.seminhematol.2018.08.009

91. Gooley TA, Chien JW, Pergam SA, Hingorani S, Sorror ML, Boeckh M, et al. Reduced Mortality after Allogeneic Hematopoietic-Cell Transplantation. N Engl J Med (2010) 363(22):2091-101. doi: 10.1056/NEJMoa1004383

92. Rubnitz JE, Inaba H, Dahl G, Ribeiro RC, Bowman WP, Taub J, et al. Minimal residual disease-directed therapy for childhood acute myeloid leukaemia: results of the AML02 multicentre trial. Lancet Oncol (2010) 11 (6):543-52. doi: 10.1016/S1470-2045(10)70090-5

93. Burnett AK, Goldstone A, Hills RK, Milligan D, Prentice A, Yin J, et al. Curability of patients with acute myeloid leukemia who did not undergo transplantation in first remission. J Clin Oncol (2013) 31(10):1293-301. doi: 10.1200/JCO.2011.40.5977

94. Pfirrmann M, Ehninger G, Thiede C, Bornhäuser M, Kramer M, Röllig C, et al. Prediction of post-remission survival in acute myeloid leukaemia: a post-hoc analysis of the AML96 trial. Lancet Oncol (2012) 13(2):207-14. doi: 10.1016/S1470-2045(11)70326-6

95. Ossenkoppele G, Schuurhuis GJ, van de Loosdrecht A, Cloos J. Can we incorporate MRD assessment into clinical practice in AML? Best Pract Res Clin Haematol (2019) 32(2):186-91. doi: 10.1016/j.beha.2019.05.003

96. Zhou Y, Othus M, Araki D, Wood BL, Radich JP, Halpern AB, et al. Pre- and post-transplant quantification of measurable ('minimal') residual disease via multiparameter flow cytometry in adult acute myeloid leukemia. Leukemia (2016) 30(7):1456-64. doi: 10.1038/leu.2016.46

97. Araki D, Wood BL, Othus M, Radich JP, Halpern AB, Zhou Y, et al. Allogeneic Hematopoietic Cell Transplantation for Acute Myeloid Leukemia: Time to Move Toward a Minimal Residual Disease-Based Definition of Complete Remission? J Clin Oncol (2016) 34(4):329-36. doi: 10.1200/JCO.2015.63.3826

98. Bataller A, Oñate G, Diaz-Beyá M, Guijarro F, Garrido A, Vives S, et al. Acute myeloid leukemia with NPM1 mutation and favorable European LeukemiaNet category: outcome after preemptive intervention based on 
measurable residual disease. Br J Haematol (2020) 1(1):1-13. doi: 10.1111/ bjh. 16857

99. Levis M, Shi W, Chang K, Laing C, Pollner R, Gocke C, et al. FLT3 inhibitors added to induction therapy induce deeper remissions. Blood (2020) 135 (1):75-8. doi: 10.1182/blood.2019002180

100. Bloomfield CD, Estey E, Pleyer L, Schuh AC, Stein EM, Tallman MS, et al. Time to repeal and replace response criteria for acute myeloid leukemia? Blood Rev (2018) 32(5):416-25. doi: 10.1016/j.blre.2018.03.006

101. Pagel JM, Othus M, Garcia-Manero G, Fang M, Radich JP, Rizzieri DA, et al. Rapid Donor Identification Improves Survival in High-Risk First-Remission Patients With Acute Myeloid Leukemia. JCO Oncol Pract (2020) 16(6):e464e75. doi: 10.1200/JOP.19.00133

102. Srour SA, Saliba RM, Bittencourt MCB, Perez JMR, Kongtim P, Alousi A, et al. Haploidentical transplantation for acute myeloid leukemia patients with minimal/measurable residual disease at transplantation. Am J Hematol (2019) 94(12):1382-7. doi: 10.1002/ajh.25647

103. Gratwohl A, Sureda A, Cornelissen J, Apperley J, Dreger P, Duarte R, et al. Alloreactivity: the Janus-face of hematopoietic stem cell transplantation. Leukemia (2017) 31(8):1752-9. doi: 10.1038/leu.2017.79

104. Yu S, Huang F, Wang Y, Xu Y, Yang T, Fan Z, et al. Haploidentical transplantation might have superior graft-versus-leukemia effect than HLA-matched sibling transplantation for high-risk acute myeloid leukemia in first complete remission: a prospective multicentre cohort study. Leukemia (2020) 34(5):1433-43. doi: 10.1038/s41375-019-0686-3

105. Gilleece MH, Labopin M, Yakoub-Agha I, Volin L, Socie G, Ljungman P, et al. Measurable residual disease, conditioning regimen intensity, and age predict outcome of allogeneic hematopoietic cell transplantation for acute myeloid leukemia in first remission: A registry analysis of 2292 patients by the Acute Leukemia Working Party European Society of Blood and Marrow Transplantation. Am J Hematol (2018) 93(9):1142-52. doi: 10.1002/ ajh. 25211

106. Dillon R, Hills R, Freeman S, Potter N, Jovanovic J, Ivey A, et al. Molecular MRD status and outcome after transplantation in NPM1-mutated AML. Blood (2020) 135(9):680-8. doi: 10.1182/blood.2019002959

107. Morsink LM, Bezerra ED, Othus M, Wood BL, Fang M, Sandmaier BM, et al. Comparative analysis of total body irradiation (TBI)-based and non-TBIbased myeloablative conditioning for acute myeloid leukemia in remission with or without measurable residual disease. Leukemia (2019). doi: 10.1038/ s41375-019-0671-x

108. Morsink LM, Sandmaier BM, Othus M, Palmieri R, Granot N, Bezerra ED, et al. Conditioning Intensity, Pre-Transplant Flow Cytometric Measurable Residual Disease, and Outcome in Adults with Acute Myeloid Leukemia Undergoing Allogeneic Hematopoietic Cell Transplantation. Cancers (2020) 12(9):2339. doi: 10.3390/cancers12092339

109. Walter RB, Gyurkocza B, Storer BE, Godwin CD, Pagel JM, Buckley SA, et al. Comparison of minimal residual disease as outcome predictor for AML patients in first complete remission undergoing myeloablative or nonmyeloablative allogeneic hematopoietic cell transplantation. Leukemia (2015) 29(1):137-44. doi: 10.1038/leu.2014.173

110. Ustun C, Courville EL, DeFor T, Dolan M, Randall N, Yohe S, et al. Myeloablative, but not Reduced-Intensity, Conditioning Overcomes the Negative Effect of Flow-Cytometric Evidence of Leukemia in Acute Myeloid Leukemia. Biol Blood Marrow Transplant (2016) 22(4):669-75. doi: 10.1016/.jbbmt.2015.10.024

111. Cloos J, Ossenkoppele GJ, Dillon R. Minimal residual disease and stem cell transplantation outcomes. Hematol Am Soc Hematol Educ Program (2019) 2019(1):617-25. doi: 10.1182/hematology.2019000006

112. Schuler E, Boughoufala S, Rautenberg C, Nachtkamp K, Dienst A, Fenk R, et al. Relapse patterns and treatment strategies in patients receiving allogeneic hematopoietic stem cell transplantation for myeloid malignancies. Ann Hematol (2019) 98(5):1225-35. doi: 10.1007/s00277019-03670-6

113. Mitani Y, Hiwatari M, Seki M, Hangai M, Takita J. Successful treatment of acute myeloid leukemia co-expressing NUP98/NSD1 and FLT3/ITD with preemptive donor lymphocyte infusions. Int J Hematol (2019) 110(4):512-6. doi: 10.1007/s12185-019-02665-3

114. Claiborne J, Bandyopathyay D, Roberts C, Hawks K, Aziz M, Simmons G, et al. Managing post allograft relapse of myeloid neoplasms: azacitidine and donor lymphocyte infusions as salvage therapy. Leuk Lymphoma (2019) 60 (11):2733-43. doi: 10.1080/10428194.2019.1605066

115. Shah N, Rakszawski K, Nickolich M, Ehmann WC, Wirk B, Naik S, et al. Improved Outcome for AML Relapse after Allogeneic Transplant with High Intensity Chemotherapy Followed By 2nd Allogeneic Stem Cell Transplant or Donor Lymphocyte Infusion; A Retrospective Analysis. Biol Blood Marrow Transplant (2020) 26(3):S99-S100. doi: 10.1016/j.bbmt.2019.12.601

116. Platzbecker U, Wermke M, Radke J, Oelschlaegel U, Seltmann F, Kiani A, et al. Azacitidine for treatment of imminent relapse in MDS or AML patients after allogeneic HSCT: results of the RELAZA trial. Leukemia (2012) 26 (3):381-9. doi: 10.1038/leu.2011.234

117. Ragon BK, Daver N, Garcia-Manero G, Ravandi F, Cortes J, Kadia T, et al. Minimal residual disease eradication with epigenetic therapy in core binding factor acute myeloid leukemia. Am J Hematol (2017) 92(9):845-50. doi: 10.1002/ajh. 24782

118. Boddu P, Jorgensen J, Kantarjian H, Borthakur G, Kadia T, Daver N, et al. Achievement of a negative minimal residual disease state after hypomethylating agent therapy in older patients with AML reduces the risk of relapse. Leukemia (2018) 32(1):241-4. doi: 10.1038/leu.2017.285

119. Nagler A, Baron F, Labopin M, Polge E, Esteve J, Bazarbachi A, et al. Measurable residual disease (MRD) testing for acute leukemia in EBMT transplant centers: a survey on behalf of the ALWP of the EBMT. Bone Marrow Transplant (2020). doi: 10.1038/s41409-020-01005-y

120. Bejanyan N, Weisdorf DJ, Logan BR, Wang H-L, Devine SM, de Lima M, et al. Survival of Patients with Acute Myeloid Leukemia Relapsing after Allogeneic Hematopoietic Cell Transplantation: A Center for International Blood and Marrow Transplant Research Study. Biol Blood Marrow Transplant (2015) 21(3):454-9. doi: 10.1016/j.bbmt.2014.11.007

121. Socié G, Stone JV, Wingard JR, Weisdorf D, Henslee-Downey PJ, Bredeson C, et al. Long-Term Survival and Late Deaths after Allogeneic Bone Marrow Transplantation. N Engl J Med (1999) 341(1):14-21. doi: 10.1056/NEJM 199907013410103

122. Shimoni A, Labopin M, Savani B, Volin L, Ehninger G, Kuball J, et al. Longterm survival and late events after allogeneic stem cell transplantation from HLA-matched siblings for acute myeloid leukemia with myeloablative compared to reduced-intensity conditioning: a report on behalf of the acute leukemia working party of European group for blood and marrow transplantation. J Hematol Oncol (2016) 9(1):118. doi: 10.1186/s13045-0160347-1

123. Puckrin R, Atenafu EG, Claudio JO, Chan S, Gupta V, Maze D, et al. Measurable residual disease monitoring provides insufficient lead-time to prevent morphologic relapse in the majority of patients with core-binding factor acute myeloid leukemia. Haematologica (2020). doi: 10.3324/ haematol.2019.235721

124. Zeijlemaker W, Kelder A, Oussoren-Brockhoff YJ, Scholten WJ, Snel AN, Veldhuizen D, et al. Peripheral blood minimal residual disease may replace bone marrow minimal residual disease as an immunophenotypic biomarker for impending relapse in acute myeloid leukemia. Leukemia (2016) 30 (3):708-15. doi: 10.1038/leu.2015.255

125. Maurillo L, Buccisano F, Spagnoli A, Del Poeta G, Panetta P, Neri B, et al. Monitoring of minimal residual disease in adult acute myeloid leukemia using peripheral blood as an alternative source to bone marrow. Haematologica (2007) 92(5):605-11. doi: 10.3324/haematol.10432

126. Boeckx N, De Roover J, van der Velden VHJ, Maertens J, Uyttebroeck A, Vandenberghe P, et al. Quantification of CBFB-MYH11 fusion gene levels in paired peripheral blood and bone marrow samples by real-time PCR. Leukemia (2005) 19(11):1988-90. doi: 10.1038/sj.leu.2403961

127. Wang Y, Wu DP, Liu QF, Qin YZ, Wang JB, Xu LP, et al. In adults with t (;) AML, posttransplant RUNX1/RUNX1T1-based MRD monitoring, rather than c-KIT mutations, allows further risk stratification. Blood (2014) 124 (12):1880-6. doi: 10.1182/blood-2014-03-563403

128. Stone RM, Mandrekar SJ, Sanford BL, Laumann K, Geyer S, Bloomfield CD, et al. Midostaurin plus Chemotherapy for Acute Myeloid Leukemia with a FLT3 Mutation. N Engl J Med (2017) 377(5):454-64. doi: 10.1056/ NEJMoa1614359

129. Ciani O, Buyse M, Drummond M, Rasi G, Saad ED, Taylor RS. Use of surrogate end points in healthcare policy: a proposal for adoption of a validation framework. Nat Rev Drug Discov (2016) 15(7):516-. doi: 10.1038/nrd.2016.81 
130. ClinicalTrials.gov. BLAST MRD AML-2: BLockade of PD-1 Added to Standard Therapy to Target Measurable Residual Disease in Acute Myeloid Leukemia 2- A Randomized Phase 2 Study of Anti-PD-1 Pembrolizumab in Combination With Azacitidine and Venetoclax as Frontline Therapy in Unfit Patients With Acute Myeloid Leukemia. National Library of Medicine (U.S.) (2020). Available at: https://ClinicalTrials.gov/show/NCT04284787.

131. ClinicalTrials.gov. Efficacy and Pharmacogenomics of Salvage CLAG-M Chemotherapy in Patients With Relapse/Refractory and Secondary Acute Myeloid Leukemia. National Library of Medicine (U.S.) (2020). Available at: https://ClinicalTrials.gov/show/NCT03150004.

132. ClinicalTrials.gov. Venetoclax and Decitabine Assessment in Patients ( $\geq 60$ $<75$ Years) With Newly Diagnosed AML Eligible for Allo-SCT. National Library of Medicine (U.S.) (2020). Available at: https://ClinicalTrials.gov/ show/NCT04476199.

133. ClinicalTrials.gov. Venetoclax and Azacitidine for Non-Elderly Adult Patients With Acute Myeloid Leukemia. National Library of Medicine (U.S.) (2020). Available at: https://ClinicalTrials.gov/show/NCT03573024.

134. ClinicalTrials.gov. Pinometostat and Azacitidine in Treating Patients With Relapsed, Refractory, or Newly Diagnosed Acute Myeloid Leukemia With 11 q23 Rearrangement. National Library of Medicine (U.S.) (2020). Available at: https:// ClinicalTrials.gov/show/NCT03701295.

135. ClinicalTrials.gov. Continuous Infusion Chemotherapy (CI-CLAM) for the Treatment of Relapsed or Refractory Acute Myeloid Leukemia or Other HighGrade Myeloid Neoplasms. National Library of Medicine (U.S.) (2020). Available at: https://ClinicalTrials.gov/show/NCT04196010.

136. ClinicalTrials.gov. BLAST MRD AML-1: BLockade of PD-1 Added to Standard Therapy to Target Measurable Residual Disease in Acute Myeloid Leukemia 1- A Randomized Phase 2 Study of Anti-PD-1 Pembrolizumab in Combination With Intensive Chemotherapy as Frontline Therapy in Patients With Acute Myeloid Leukemia. National Library of Medicine (U.S.) (2020). Available at: https:// ClinicalTrials.gov/show/NCT04214249.

137. ClinicalTrials.gov. Improved Post-Transplant Cyclophosphamide Regimens for Pediatric Patients With Refractory AML [Internet]. National Library of Medicine (U.S.) (2020). Identifier: NCT03654703. Available at: https:// ClinicalTrials.gov/show/NCT03654703.

138. Tiong IS, Dillon R, Ivey A, Teh TC, Nguyen P, Cummings $\mathrm{N}$, et al. Venetoclax induces rapid elimination of NPM1 mutant measurable residual disease in combination with low-intensity chemotherapy in acute myeloid leukaemia. Br J Haematol (2020). doi: 10.1111/bjh.16722

139. ClinicalTrials.gov. Fractionated Gemtuzumab Ozogamicin in Treating Measurable Residual Disease in Participants With Acute Myeloid Leukemia. National Library of Medicine (U.S.) (2020). Available at: https://ClinicalTrials.gov/show/NCT03737955.

140. ClinicalTrials.gov. Clofarabine, Cyclophosphamide and Etoposide for Minimal Residual Disease Positive Acute Leukemia. National Library of Medicine (U.S.) (2020). Available at: https://ClinicalTrials.gov/show/ NCT01677949.

141. ClinicalTrials.gov. Clofarabine and Cytarabine in Treating Patients With Acute Myeloid Leukemia With Minimal Residual Disease. National Library of Medicine (U.S.) (2020). Available at: https://ClinicalTrials.gov/show/ NCT00863434.

142. ClinicalTrials.gov. Efficacy and Safety of Immunotherapy With Allogeneic Dendritic Cells, DCP-001, in Patients With Acute Myeloid Leukaemia. National Library of Medicine (U.S.) (2020). Available at: https:// ClinicalTrials.gov/show/NCT03697707.

143. ClinicalTrials.gov. Efficacy of Decitabine in Clearance of MRD. National Library of Medicine (U.S.) (2020). Available at: https://ClinicalTrials.gov/ show/NCT03021395.

144. ClinicalTrials.gov. Gemtuzumab Chemotherapy MRD Levels; Glasdegib Posttransplant, Adult Untreated, de Novo, Fav Interm Risk AML. National
Library of Medicine (U.S.) (2020). Available at: https://ClinicalTrials.gov/ show/NCT04168502.

145. ClinicalTrials.gov. Gemtuzumab Ozogamicin in Induction and Glasdegib in Postremission Therapy in Patients With AML (Acute Myeloid Leukemia). National Library of Medicine (U.S.) (2020). Available at: https:// ClinicalTrials.gov/show/NCT04093505.

146. ClinicalTrials.gov. Personalized Targeted Preparative Regimen Before Tdepleted Allogeneic HSCT in Children With Chemoresistent Acute Leukemias. National Library of Medicine (U.S.) (2020). Available at: https://ClinicalTrials.gov/show/NCT04000698.

147. ClinicalTrials.gov. Safety and Clinical Activity Study of Combination Azacitidine and Avelumab in Patients With Acute Myeloid Leukemia (AML) and Minimal Residual Disease (MRD). National Library of Medicine (U.S.) (2020). Available at: https://ClinicalTrials.gov/show/ NCT03699384.

148. ClinicalTrials.gov. A Study of Vadastuximab Talirine Given Prior to or After Allogeneic Hematopoietic Stem Cell Transplant in AML Patients. National Library of Medicine (U.S.) (2020). Available at: https://ClinicalTrials.gov/ show/NCT02614560.

149. ClinicalTrials.gov. Natural Killer-cell Therapy for Acute Myeloid Leukemia. National Library of Medicine (U.S.) (2020). Available at: https:// ClinicalTrials.gov/show/NCT04347616.

150. Prebet T, Bertoli S, Delaunay J, Pigneux A, Delabesse E, Mozziconacci MJ, et al. Anthracycline dose intensification improves molecular response and outcome of patients treated for core binding factor acute myeloid leukemia. Haematologica (2014) 99(10):e185-e7. doi: 10.3324/haematol.2014.109827

151. Lambert J, Lambert J, Nibourel O, Pautas C, Hayette S, Cayuela JM, et al. MRD assessed by WT1 and NPM1 transcript levels identifies distinct outcomes in AML patients and is influenced by gemtuzumab ozogamicin. Oncotarget (2014) 5(15):6280-8. doi: 10.18632/oncotarget.2196

152. Gianfaldoni G, Mannelli F, Intermesoli T, Bencini S, Giupponi D, Farina G, et al. Early peripheral clearance of leukemia-associated immunophenotypes in AML: centralized analysis of a randomized trial. Blood Adv (2020) 4 (2):301-11. doi: 10.1182/bloodadvances.2019000406

153. Walter RB, Estey EH. Selection of initial therapy for newly-diagnosed adult acute myeloid leukemia: Limitations of predictive models. Blood Rev (2020) 100679. doi: 10.1016/j.blre.2020.100679

154. Hoffmann K, Cazemier K, Baldow C, Schuster S, Kheifetz Y, Schirm S, et al. Integration of mathematical model predictions into routine workflows to support clinical decision making in haematology. BMC Med Inform Decis Mak (2020) 20(1):28-. doi: 10.1186/s12911-020-1039-x

155. Gerstung M, Papaemmanuil E, Martincorena I, Bullinger L, Gaidzik VI, Paschka $\mathrm{P}$, et al. Precision oncology for acute myeloid leukemia using a knowledge bank approach. Nat Genet (2017) 49(3):332-40. doi: 10.1038/ng.3756

156. HARMONY consortium. HARMONY Big Data Platform. ARMONY Communications European Hematology Association (2020). Available at: https://www.harmony-alliance.eu/bigdata-platform/hematology-big-dataplatform.

Conflict of Interest: The authors declare that the research was conducted in the absence of any commercial or financial relationships that could be construed as a potential conflict of interest.

Copyright (c) 2021 Ngai, Kelder, Janssen, Ossenkoppele and Cloos. This is an openaccess article distributed under the terms of the Creative Commons Attribution License (CC BY). The use, distribution or reproduction in other forums is permitted, provided the original author(s) and the copyright owner(s) are credited and that the original publication in this journal is cited, in accordance with accepted academic practice. No use, distribution or reproduction is permitted which does not comply with these terms. 